\title{
Expansion of IFC model with structural sensors
}

\section{Expansión del modelo IFC con sensores estructurales}

\author{
L. Rio $^{(*)}$, B. Ferreira ${ }^{(*)}$, J. Poças-Martins(*)
}

\section{SUMMARY}

The instrumentation and structural health monitoring, SHM, of buildings is a growing field in the construction industry. The goal of this research work is to explore ways of modeling SHM systems, and the resulting data collected from buildings, in standard information management system such as Building Information Models, BIM. These models need to be stored in digital databases with structures suitable for the specific building related information. In this work the Industry Foundation Classes, IFC, data model was used.

A case study is presented to assess the applicability of the present IFC standard as a tool to build a three-dimensional digital model of a real instrumented building, as well as some of the structural sensors and their results. The interoperability of the digital model was verified by using different modeling, viewing and analysis software tools. Limitations of the current IFC model were explored and extensions to the sensor classes are proposed.

458-10

Keywords: Structural Health Monitoring; building structures; information management; BIM; IFC.

\section{RESUMEN}

La instrumentación y monitorización de la salud estructural de edificios, SHM, es un campo creciente en la industria de la construcción. El objetivo del presente trabajo es estudiar la modelación de sistemas SHM tomados de edificios en un modelo digital BIM e la sua integración de datos. Estos modelos deben almacenarse en bases de datos con una estructura apropiada para albergar información específica relacionada con la construcción. En este trabajo se utilizó el estándar Industry Foundation Classes, IFC.

Se presenta un estudio de caso para evaluar la norma IFC como herramienta para modelar un edificio real instrumentado, así como algunos sensores estruturales e sus resultados. La inter-operatividad de lo modelo digital se ha comprobado mediante el uso de diferentes herramientas de software de modelación, visualización y análisis. Se exploran además limitaciones del modelo IFC y se proponen extensiones de las clases de sensores.

Palabras clave: Monitorización de la salud estructural; estructuras de edificios; gestión de la información; BIM; IFC.

\footnotetext{
(*) Universidade do Porto (Portugal). 


\section{INTRODUCTION}

\subsection{Building Information Models}

Building Information Models, BIM, is a relatively novel solution to the design, construction and management in the construction industry, including engineering and architecture. It enables the digital modelling of a building, centralizing and integrating relevant information with associated principles of automation and integration (1). Proper information management is significantly important because it represents the basis for communicating, allowing the establishment of an interoperable model of a building, containing the various disciplines of an existing project, information for each individual component of that building, and of its life cycle. These models can be so complete as to form a digital building (2).

One of the challenges in information management systems in general, and of those that are geared towards the construction industry in particular, is the standardization of the information. To address this issue, several initiatives have been established to create a standard for the representation and organization of construction products, among which the Industry Foundation Classes, IFC, stands out due to the fact that it has achieved the status of an ad-hoc standard format. The IFC model is currently an open-exchange format that is compatible with various BIM applications, that allows standardizing the construction process (3). BIM use in the construction industry has the potential of changing the paradigm of how the design and construction teams communicate with each other (4).

There are several standards for representing information and data of entities and structures, such as the international standards for products, ISO 103031994 (5), known as STEP, STandards for the Exchange of Product model data. IFC, developed by the International Alliance for Interoperability, IAI, presently known as buildingSMART, is a standard data format for BIM (6), coherent with the STEP standards (7). The IFC is an objectbased building data model that is non-proprietary, similar to other rich object based data models used in other proprietary applications (8), much the same way as HTML is a standard for internet communication.

\subsection{Structural Health Monitoring}

Structural Health Monitoring, SHM, can be defined as a non-destructive in situ assessment of structural behaviour, health, condition or damage identification (9) (10). To this end, different types of structural and environmental sensors, which are responsible for continuous or periodic gathering of information, need to be installed. The data generated is eventually collected, transmitted, assessed and stored for analysis. From such analysis, the structure stakeholders can, making use of behaviour models, evaluate the behaviour of the structures, including its safety, integrity, performance and damage detection (9). Take the example of important bridges and buildings that are already instrumented, and that after suffering an earthquake event, their structural integrity can be evaluated in real time before they are allowed to be opened for public use (11) (12). Another application is the capture of the project history itself (13).

The amount of data generated is a function of the number of sensors and of their acquisition and sampling rates (12) (14). It can vary by large amounts depending if the sensors are mainly static with lower sampling rates, or dynamic, with higher sampling rates. The management of all the original raw data, as well as of all the post-processed data, during the entire life-cycle of the infrastructure, that can add up to hundreds of Giga, of even Terabits, can constitute a problem, in particular if all the original data is kept for future processing (15).

The integration of SHM in buildings with BIM technology is still considered to be a future development (1), accordingly the literature review produced little or no known references for this particular subject. The goal of the present work was to bridge between the real world, as measured in a specific SHM data set, and the digital world, as modeled by BIM, for which the results, conclusions and potential model development suggestions are presented next.

\section{DATA STRUCTURE OF THE IFC MODEL USED IN SHM}

\subsection{General Aspects}

Because the IFC is an open data exchange format that captures building information, it can be used by commercial and noncommercial building-model based applications to exchange data with each other (8). The IFC model represents tangible building components such as doors, walls, ceilings, beams, etc., and more abstract entities like time schedules, spaces, activities, construction costs, organization, etc. These entities have a number of attributes like their name, geometry, materials, finishes, relationships, and so on (8). The IFC model uses the particular EXPRESS data definition language given in ISO 10303-11 (16) (17), a subset of the STEP language (5). 
The architecture of the IFC model provides a framework for the development of modular components of the model. There are four conceptual layers within the architecture, using a strict hierarchical reference. Within each layer a set of conceptual model schemas is defined. The first conceptual layer provides resource classes used by classes in the higher levels. The second layer provides a nuclear conceptual model design. This core contains kernel and several core extensions. The third conceptual layer provides a set of modules defining concepts or common objects in many types of applications or areas of the construction industry. This is the interoperability layer. Finally, the fourth and highest layer of the IFC is the Domains layer. This provides a set of modules tailored to the specific area of the construction industry or type of application. In addition, this layer contains specialized model "adapters" for domains/application models that are not included in the IFC model architecture. The architecture of the model operates with a "principle of stairs". In any layer, a class can reference another class in the same layer or at the inferior level, but cannot reference a class from a higher layer. References in the same layer must be designed very carefully in order to maintain modularity in the design of the model (1).

The role of the domain layer is to organize definitions of entities according to industry discipline, e.g., architecture, structures, AVAC, etc. It includes the Building Controls Domain module that defines the concepts of building automation, control, instrumentation and alarm systems, which can be used across different construction disciplines, including SHM:

- Actuator.

- Alarm.

- Controller.

- Sensor.

- Flow instrument.

- Unitary control element.

Sensors are an integral part of SHM systems. They are physical objects attached or included in the building elements with properties that define their purpose and the way they operate. These entities may, like other building elements, be represented in 3D BIM models, which can then be used to store the obtained SHM data.

\subsection{Specific Sensor Aspects}

Sensors are included in the IfcBuildingControlsDomain module. A sensor is a device that measures a physical quantity and converts it into a signal that can be read by an observer or instrument. Inside IFC there are two classes concerned with sensors, which are IfcSensor and IfcSensorType. The IfcSensor defines the sensor properties which are used to read the occurrences of specific sensors. The common information shared within types of sensors is dealt by the IfCSensorType that may include:

- Common properties with shared property sets.

- Common representations of shape.

- Common materials.

- Common composition of elements.

- Common ports.

- Applicable assignment of process types.

The IfcBuildingControlsDomain domain takes information from the design and can also host real time information through IfcPerformanceHistory. The control systems can be assigned to this entity. In this case the user needs to create Property Sets, not part of the standard (18), in which to store the data. Unfortunately sensors cannot yet take advantage of the IfcPerformanceHistory (17).

The range of different types of sensors that can be specified are enumerated, without any functional criteria, under IfcSensorTypeEnumm (14) (17). Each sensor type has in turn its own specific set of properties, given by Pset_SensorName which defines the different types of readings or other relevant information stored by the specific IfcSensor class. These should not be confused with the IFC model's generic customizable property sets, IfcPropertySet. These can be personalized to handle different types of information, as best suits the modeler. These generic property sets are less transferable, in the sense that the existing software tools will only be able to handle them in a limited way.

\section{STRUCTURAL HEALTH MONITORING}

\subsection{Architecture}

Buildings are complex systems. Their analysis involves a number of different fields of knowledge as well as a suite of different software tools, not always interoperable between each other (19) (20). The purpose of the instrumentation and monitoring of structures is to understand the building behavior in situ with accuracy and efficiency, to evaluate their performance over different loads in service, to detect damage or deterioration, i.e., to determine the health and condition of the structure. Structural Health Monitoring should be able to provide reliable information regarding the safety and integrity of the structure (21). 


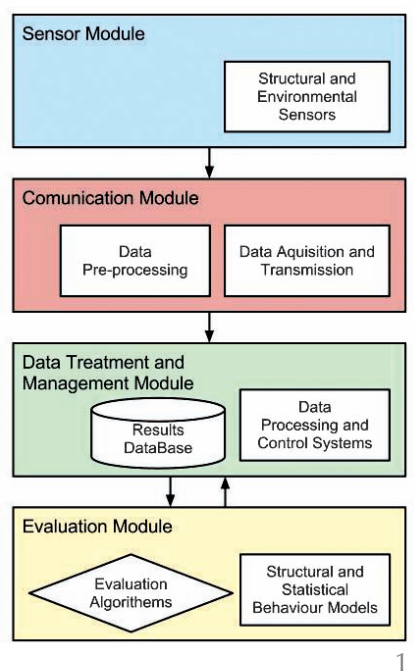

1. Structural Health Monitoring system architecture.
Nowadays, the monitoring systems allow the acquisition, storage and analysis of data collected from installed sensors at feasible costs (10). There has been an enormous development in these devices, especially with regard to the quality of the measurement, the frequency of acquisition and storage and processing of information. It is expected that these systems are able to provide information as detailed as possible about the structural behavior. They can be the bridge between the real world and the digital/virtual world.

Despite there not being a single high level SHM system architecture, it can be usually organized in several mains components or modules, I) the sensors module, II) the communication module, III) the results data treatment and management module, and sometimes an IV) evaluation module (22) (23), see Figure 1.

Such a SHM system can be composed by a sensors network throughout the structure, connected to an acquisition and transmission system that interrogates the sensors and a pre-processing routine that, adjusts the signals. These results can then be processed and transformed into concrete information to assess the structural behavior and stored for future use, see scheme in Figure 1. If an evaluation is made, then numerical models with the structural information available can be calibrated, for each monitored element and of the structure as a whole (15).

Some of the information concerning the SHM systems can be stored in a digital model such as a BIM, which seems to be suitable to represent the sensors, the data acquisition and transmission equipment and the actual building or infrastructure. Potentially, it could also include each sensor's data records.

\subsection{Sensors}

There are countless types of sensors, as well as things to measure. The most frequently used variables in civil engineering SHM are briefly described in this section, along with the sensors used to measure them. Due to the kinematic nature of the majority of the monitored behaviors, this sensors group could be called kinematic within the IFC data model.

\subsubsection{Displacements}

To measure the relative displacements between two points there is a wide range of devices. One often used type is that of the Linear Variable Differential Transformer, LVDT, inductive transducers where the displacement is obtained indirectly, through the variation of an induced current in a solenoid by the displacement of a magnetic core inside.

\subsubsection{Rotations}

The rotation of a structure can be measured by two processes with different principles. The first is through the angular variation of a given axis between a start position and an end position while the other is through the angular deviation of a given axis in relation to a reference plane that is fixed. For the measurement of the angular variations and absolute rotation clinometers and inclinometers are used respectively.

\subsubsection{Strains}

The measurement of a strain at a point is obtained by evaluating the length variation over the original length of a segment. The reference length may be higher or lower depending on the homogeneity of the material. The sensors used in structural monitoring for this purpose are called strain gauges. Notice that there are a number of different types of strain gauges, e.g., for application in different structural materials.

\subsubsection{Temperatures}

Currently there are a wide variety of sensors to measure temperature with different characteristics, such as measuring range and linearity, which makes them particularly suitable for certain specific applications. The current sensors in the structural health monitoring are thermocouples and resistance temperature detector (RTD).

\subsubsection{Acquisition System}

The acquisition system is the element responsible for receiving, conditioning, storing and transmitting the readings obtained by the sensors. This system allows the interrogation of signals from the sensors and stores this information locally or makes it available in a data network. The system may contain acquisition boards integrated into computers or standalone operation dispensing equipment permanently connected to computers.

\section{CASE STUDY APPLICATION / INTEROPERABILITY TEST}

A practical case study was carried out on an independently instrumented building, where existing monitoring data of its structure and foundation was included on a new BIM model. The goal was to study the feasibility of including this type of information, enabling it to be shared in a structural analysis. 
The underlying data structure considered was the IFC model version $2 \times 3$, which up to the submission of this paper is the latest stable version approved by buildingSMART [1], and was the one used by the BIM software tools available.

A generic BIM model of the studied building was created in commercially available BIM modeling software, ArchiCAD v14. This model was then parsed as a global complete model and as a structural only relevant information model; both saved as IFC file types. The compatibility of these conversions was tested by inspecting the model in an independent model viewer software, Solibri. This parsing of the model is similar to other flows of information between generic modeling software and specific simulation software (25).

In order to understand the flow of information between such a generic BIM model and a structural design model, the IFC version of the building model was opened and manipulated by different Autodesk structural analysis tools, namely: Robot Structural Analysis 11 and Concrete Building Structures 11, see Figure 2.

The data exchange process illustrated in the diagram shown in Figure 2 describes the initial modeling of the architectural, structural and instrumentation design in the modeling software. Using the IFC as an exchange format, the model was then opened in the model viewer software, which permits the visualization of the sensor readings. At this stage, abnormal readings can be detected and lead to decision making by the Structural Engineer for example. After this simple inspection process, a more detailed evaluation can be performed by structural analysis software, which can lead to a redesign based on sensor data. The process can repeat itself cyclically by going back to the initial modeling tool to implement the obtained structural rectifications.

\subsection{Modeling of the Building}

An existing building located at FEUP's campus (Faculdade de Engenharia da Universidade do Porto) was chosen as a case study for integrating SHM information in a standard BIM model. This building has vibrating wire sensors integrated into the structure installed during its construction. To model it correctly, and introduce the sensors in the right places, the original building plants were consulted together with site visits. Since the existing IFC versions do not include the relevant kinematic sensors, neither do the proprietary model structures of the modeling software, a smoke sensor type was used as a proxy. This way it would be possible to have an object which is visible in the different software. The specific property sets for this sensor type needed to be replaced by a custom property set to enable the storage of the vibrating wire sensor specific's data. A view with the final building model and of the building itself is given in Figure 3.

Having completed the three-dimensional model in the modeling software, it was converted in an IFC $2 \times 3$ data file. An initial visual verification of the conversion was made using a model viewer, in particular the confirmation that all the elements including the sensors had been correctly converted, i.e., were modeled as IFC objects. This step was important because the IFC file was edited in a simple text editor such as Windows Notepad, where small corrections and additions were made. This inspection task was performed using the model viewer software, where the text data can also be visualized. It should be noted that this verification procedure is not completely satisfactory. It is a manual process and it relies on visual inspection. Specific modeling rules should be defined and documented for SHM purposes, as has been done in other domains (26), and automated methods for BIM quality assessment should be developed.
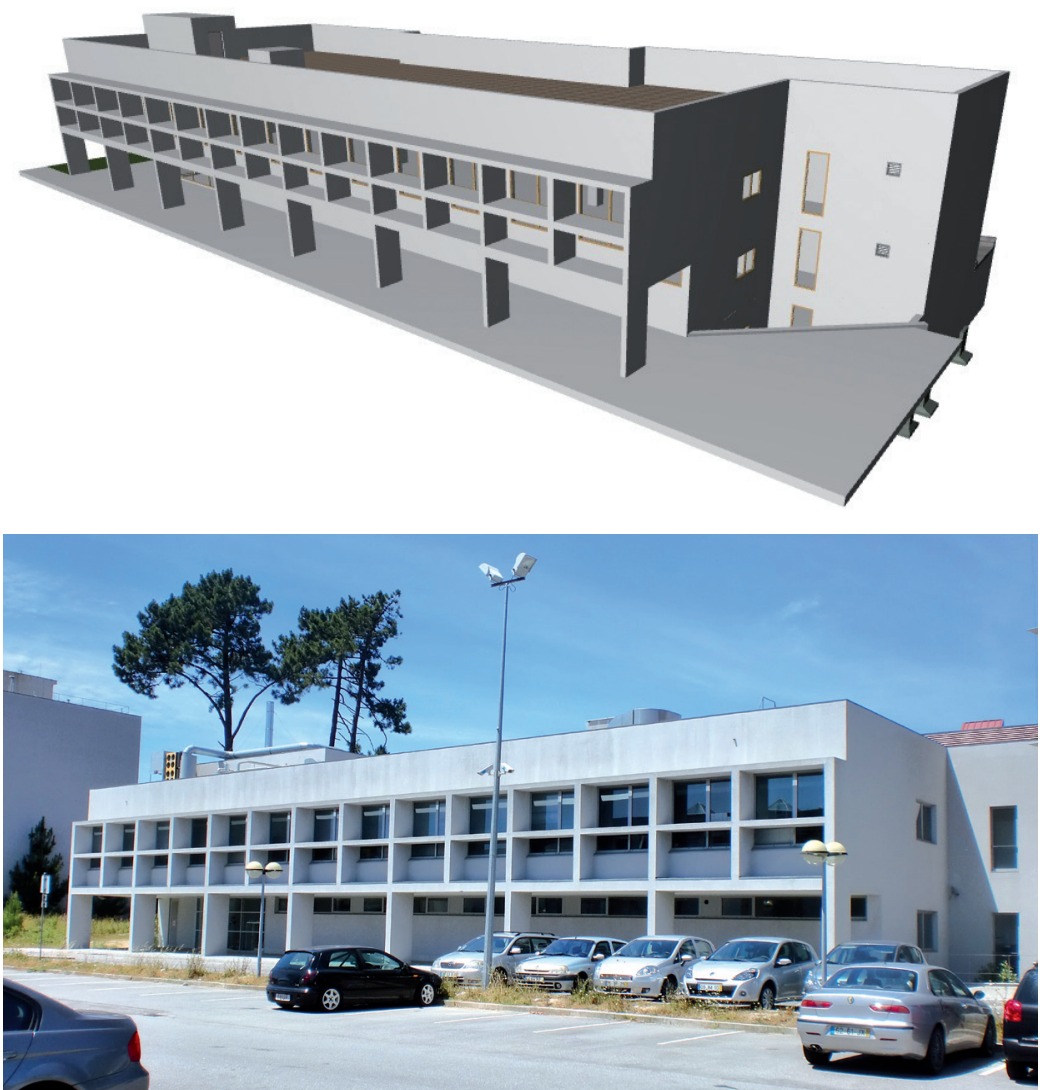

2. Structural model information flow.

3. View of the BIM model and the actual building.

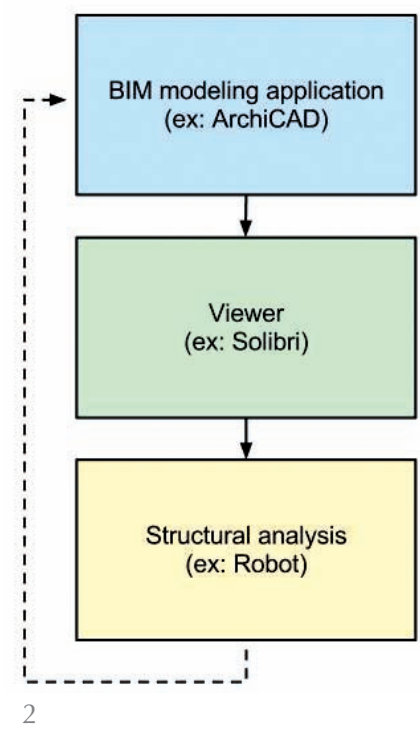


4. Visualization of the Property Sets in modelling software, ArchiCad V14.

5. View of the IFC file in the text editor.

6. Final result of the created Property set.

\subsection{Property Set Creation}

Regarding the addition of information from the sensors, a new generic custom Property Set needed to be created, compatible with the existing entity IfcSensorType. For the purpose of creating the new custom Property Set, an example of another existing specific sensor, a heat sensor, is shown with its definition and properties taken from the IFC documentation (17), and given in Table 1 and Table 2.

The proposed new custom Property Set for the Vibrating Wire Strain Gauge sensor was created based on the Heat Sensor Pset_SensorTypeHeatSensor scheme and its definition and properties shown in Table 3 and Table 4.

The generic Property Set of the Vibrating Wire Strain Gauge sensor was defined so as to handle the frequency of vibration, which this sensor measures. In addition to this parameter the sensor records the temperature at the time of each vibration frequency measurement, since these sensors need a correction factor that is a function of such temperature. The extension is calculated based on the corrected vibration frequency with a known degree of accuracy. Each sensor is connected to a specific building element, and to know which sensor is related to each element the SetRelations property is added. Also, the sensor is typically connected to a data acquisition system, which registers the date and time of each measurement. The relation between each sensor and the data acquisition system to which it is connected can also be formalized in the model, even though this was not implemented in the present case study.

After the property sets creation, their interoperability and functionality were verified sequentially in a text editor, in a model viewer and again in the original modeling software, Figure 4. In this example, five simple values were introduced in each definition. It was possible to introduce the list of sensor values in the right text format. It was observed that if an inadequate text format is used the model file becomes corrupted and cannot be opened by the other applications.

Having confirmed the viability of the new custom Property Set with some simple values, the next step was to fill-in the actual sensors data, Figure 5. This data entry must be done using the text editor software, since when the modeling software was used; it sorted the values according to ascending order and not according to date and time of entry as desired. Also, the modeling software eliminated repeated values, despite being from different readings. This is a clear case of a lack of suitability of existing soft-

Table 1. Heat Sensor Property Set definition, as given in buildingSMART (1)

\begin{tabular}{|l|l|}
\hline PropertySet Name & Pset_SensorTypeHeatSensor \\
\hline Applicable Entities & IfCSensorType \\
\hline Applicable Type Value & IfcSensorType/HEATSENSOR \\
\hline Definition & Definition from IAI: A device that senses or detects heat. \\
\hline
\end{tabular}

Table 2. Heat Sensor Property Set properties, as given in buildingSMART (1)

\begin{tabular}{|l|l|l|l|}
\hline Name & Property Type & Data Type & Definition \\
\hline $\begin{array}{l}\text { Coverage } \\
\text { Area }\end{array}$ & IfcPropertySingleValue & $\begin{array}{l}\text { IfCAreaMeasure } \\
\text { / AREAUNIT }\end{array}$ & $\begin{array}{l}\text { The area that is covered by the sensor } \\
\text { (typically measured as a circle whose } \\
\text { center is at the location of the sensor). }\end{array}$ \\
\hline $\begin{array}{l}\text { Set Point } \\
\text { Temperature }\end{array}$ & IfCPropertyBoundedValue & $\begin{array}{l}\text { IfCThermodynamicTemperatureMeasure } \\
\text { /THERMODYNAMICTEMPERATUREUNIT } \\
\text { LowerBound: } \\
\text { UpperBound: }\end{array}$ & $\begin{array}{l}\text { The temperature value to be sensed. Use } \\
\text { IfcPropertyBoundedValue.SetPointValue to } \\
\text { set the set point value. }\end{array}$ \\
\hline $\begin{array}{l}\text { Rate Of } \\
\text { Temperature Rise }\end{array}$ & IfCPropertySingleValue & $\begin{array}{l}\text { IfCTemperatureRateOfChangeMeasure } \\
\text { /TEMPERATURERATEOFCHANGE }\end{array}$ & $\begin{array}{l}\text { The rate of temperature rise that is to be } \\
\text { sensed as being hazardous. }\end{array}$ \\
\hline
\end{tabular}

Table 3. Vibration Wire new Property Set definition

\begin{tabular}{|l|l|}
\hline PropertySet Name & Pset_SensorTypeVibratingWireSensor \\
\hline Applicable Entities & IfcSensorType \\
\hline Applicable Type Value & IfcSensorType/VIBRATINGWIRESENSOR \\
\hline Definition & Definition: A device that detects vibrations for the extensions calculation \\
\hline
\end{tabular}

Table 4. Vibrating Wire new Property Set properties

\begin{tabular}{|l|l|l|l|}
\hline Name & Property Type & Data Type & Definition \\
\hline SetPointFrequence & IfCPropertyListValue & $\begin{array}{l}\text { IfCFrequencyMeasure } \\
\text { / FREQUENCEUNIT }\end{array}$ & $\begin{array}{l}\text { The frequency value to be sensed. Use } \\
\text { IfcPropertyBoundedValue.SetPointValue } \\
\text { to set the set point value. }\end{array}$ \\
\hline SetPointTemperature & IfCPropertyListValue & $\begin{array}{l}\text { IfCThermodynamicTemperatureMeasure } \\
\text { /THERMODYNAMICTEMPERATUREUNIT }\end{array}$ & $\begin{array}{l}\text { The temperature value to be sensed. Use } \\
\text { IfcPropertyBoundedValue.SetPointValue } \\
\text { to set the set point value. }\end{array}$ \\
\hline SetDateTime & IfCPropertyListValue & IfCDateTime & $\begin{array}{l}\text { The date and time for each measured } \\
\text { value. }\end{array}$ \\
\hline SetRelations & IfCLabel & $\begin{array}{l}\text { Relation between the sensor and the } \\
\text { building element in study. }\end{array}$ \\
\hline
\end{tabular}


ware BIM tools to handle sensor data. Note that each element has a global unique identifier, known as GUID.

After the introduction of the full set of real sensor data for each sensor the model viewer was used to check its consistency as illustrated in Figure 6.

As can be seen in Figure 6, the data obtained in the test was stored consistently at the custom Property Set created for this purpose. The order of the data records is maintained and no values have been deleted, as was the case when the modeling software was used to insert this data. The stored values are the raw data which can then be used in a number of ways.

To understand the usability of the case study model a three-dimensional view of a sensor, selected and highlighted in green is given in Figure 7. Note that the related sensor information tab shows the properties of the sensor as well as the recorded values stored through the purposely built Property Set.

\subsection{Potential applications}

Data stored in IFC files can be accessed by external applications or by functions that may be included in the IFC data model itself. These external and IFC level functions can potentially be used to handle data, for example to calculate strain from vibration frequency in vibrating wires strain gauges. External applications, such as structural analysis programs may be supplied with SHM data to assess the impact of displacements, temperature variations or other events in real time. In such case, these functions could also be used to compare with externally obtained reference values. Such comparison can, in turn, lead to the triggering of automatic or human tasks. For example, a building can be evacuated if a displacement sensor detects large foundation displacements. However the implementation of function processes was not carried out within the scope of this work.

\section{PROPOSED IFC MODEL CLASSES}

The IFC model, in stable version $2 \times 3$, determines sensor occurrences by using the class IfcSensor, for which there are a number of predetermined sensor types defined by its IfcSensorType, e.g., fire sensor (Pset SensorTypeFireSensor), temperature sensor (Pset_SensorTypeTemperatureSensor) or light sensor (Pset_SensorTypeLightSensor). The full enumeration of sensor types at IfcSensorTypeEnum class are described in the IFC documentation (27). The present IFC model version includes mainly environmental sen- sors but does not include specific structural kinematic sensors. It does allow for some flexibility by including generic IfcSensorType Enumerations such as USERDEFINED and NOTDEFINED.

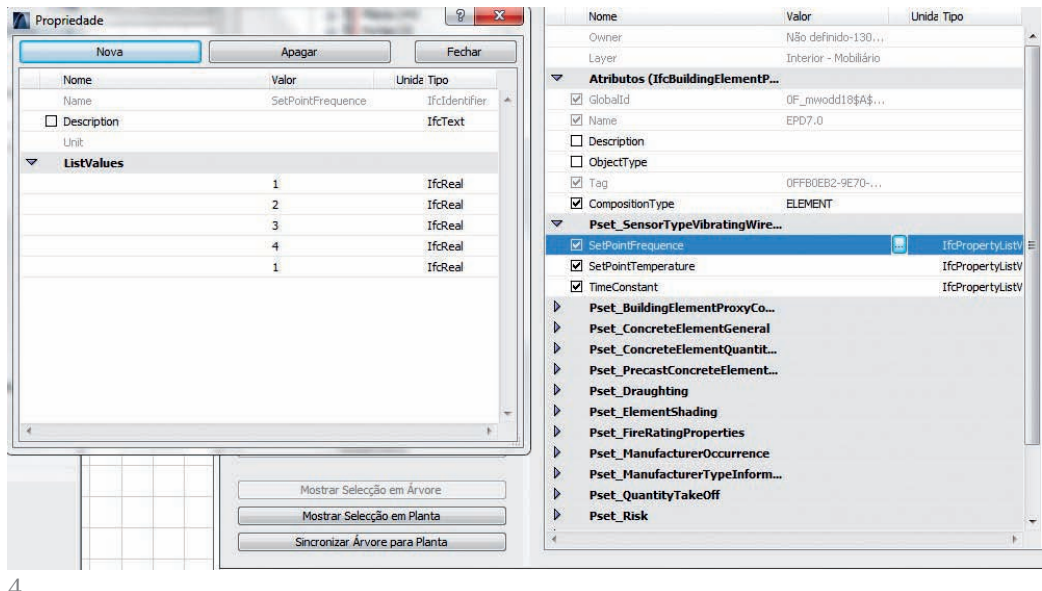

\#293102), \#1299);

$\# 293442=$ IFCCARTESIANTRANSFORMATIONOPERATOR3D $(\$, \$, \# 40,1 ., \$)$;

\#293448= IFCSHAPEREPRESENTATION (\#51, 'Body' , 'MappedRepresentation' , (

$\# 293445))$;

\#293454= IFCPRODUCTDEFINITIONSHAPE (\$, \$, (\#293448));

$\# 293458=$ IFCCARTESIANPOINT ( $(30688.624,-26170.467,-300)$.$) ;$

$\# 293462=$ IFCAXIS2PLACEMENT3D (\#293458,\#36,\#28);

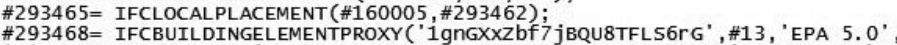

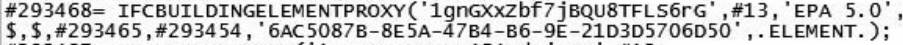

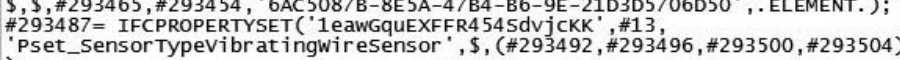

);

IFCREAL (766.78), IFCREAL (766.67), IFCREAL (766.78), IFCREAL (766. 80), IFCREAL (

766.70), IFCREAL (766.69), IFCREAL (766.7), IFCREAL (766.77), IFCREAL (766.69),

IFCREAL (766.7), IFCREAL (766. 77), IFCREAL (766. 69), IFCREAL (766.72), IFCREAL (
766. 61), IFCREAL (766. 69), IFCREAL (766.59), IFCREAL (766.67), IFCREAL (766. 8),
IFCREAL (766.7), IFCREAL (766.72), IFCREAL (766.72), IFCREAL (766.81), IFCREAL(

766.69), IFCREAL (766.69), IFCREAL $(766.64)$, IFCREAL $(766.67)$, IFCREAL $(766.84)$

IFCREAL (766. 66)), \$);

\#293496 = IFCPROPERTYLISTVALUE (' setPointTemper ature' , \$, (IFCREAL (8. 57),

IFCREAL (8. 58), IFCREAL (8.58), IFCREAL (8.58), IFCREAL (8. 59), IFCREAL (8.59), IFCREAL

(8. 59), IFCREAL (8. 59), IFCREAL (8. 59), IFCREAL (8. 59), IFCREAL (8. 59), IFCREAL

(8. 59), IFCREAL (8.59), IFCREAL (8.59), ,IFCREAL (8.59), ,IFCREAL (8. 59), ,IFCREAL

(8. 59), IFCREAL (8. 59), IFCREAL (8. 59), IFCREAL ( 8. 59), IFCREAL (8. 59), IFCREAL

(8.58), IFCREAL (8.59), IFCREAL (8.59), IFCREAL ( 8.59 ), IFCREAL $(8.59)$ ), \$);

$\# 293500=$ IFCPROPERTYSINGLEVALUE ('SetRelations ' '\$, IFCLABEL ('PD5.0'), \$);

28-12-2006 10:45:51'), IFCLABEL ('28-12-2006 10:45:52'), IFCLABEL ('28-12-2006

$\left.10: 45: 53^{\prime}\right)$, IFCLABEL ( $\left.28-12-2006 \quad 10: 45: 54^{\prime}\right)$, IFCLABEL (' $28-12-2006$

$10: 45: 55$, IFCLABEL ( $28-12-2006$ 10:45:56), IFCLABEL ( 28-12-2006

$\left.10: 45: 57^{\prime}\right)$, , IFCLABEL ('28-12-2006 10:45:58', ', IFCLABEL ('28-12-2006

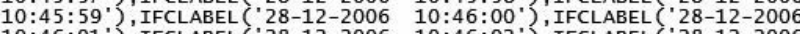

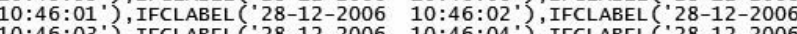

10:46:03, , IFCLABEL ( 28-12-2006 10:46:04, , IFCLABEL, $28-12-2006$

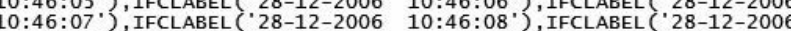

0:46:09' $\{$, IFCLABEL ( $28-12-2006$ 10:46:10' $\}$ ', IFCLABEL ( $28-12-2006$

$10: 46: 11$ ' ', ', IFCLABEL (' $28-12-2006 \quad 10: 46: 12$ ' ', IFCLABEL (' $28-12-2006$

$10: 46: 13$,$\} , IFCLABEL ( ' 28-12-2006 10: 46: 14$,$\} , IFCLABEL (' 28-12-2006$

$\left.10: 46: 15^{\prime}\right)$,IFCLABEL ('28-12-2006 $\left.10: 46: 16^{\prime}\right)$, ', \$);

\#293511= IFCRELDEFINESBYPROPERTIES (' 3XtaqXBALO6wSpCXvJ0Bar' , \#13,\$, \$,

\#293468) $\# 293487$ )

\#293513 = IFCPROPERTYSINGLEVALUE ('ArChiCAD_GUID' , \$, IFCDESCRIPTIVEMEASURE(

6AC5087B-8E5A-47B4-B6-9E-21D3D5706D50') '\$);
\#293517 = IFCPROPERTYSINGLEVALUE ('LAYERNAME'; \$, IFCDESCRIPTIVEMEASURE(

\#293517= IFCPR

\#293521= IFCPROPERTYSINGLEVALUE( ('INFO' , \$, IFCDESCRIPTIVEMEASURE('EPA $5.0^{\prime}$ ),\$);

5

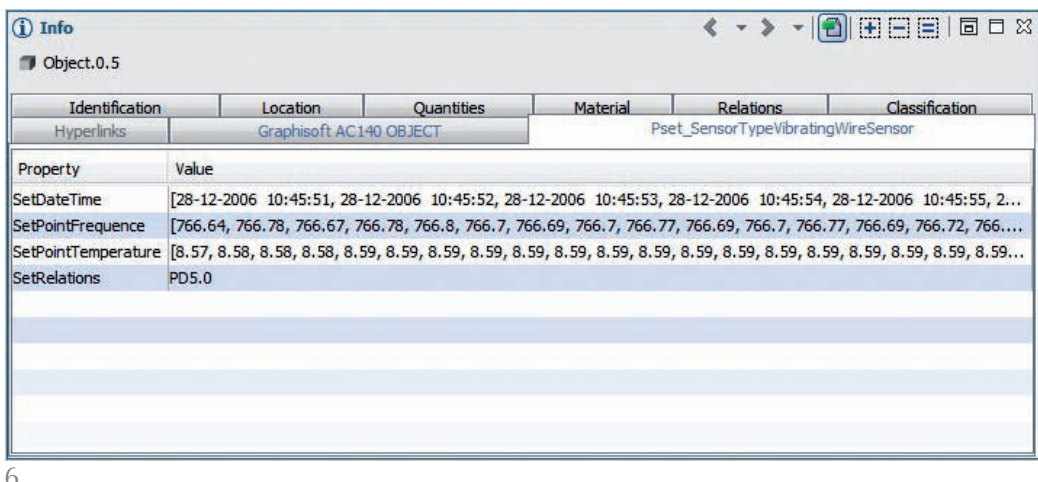


7. Visualization of the information by selecting the sensor in the three-dimensional model.

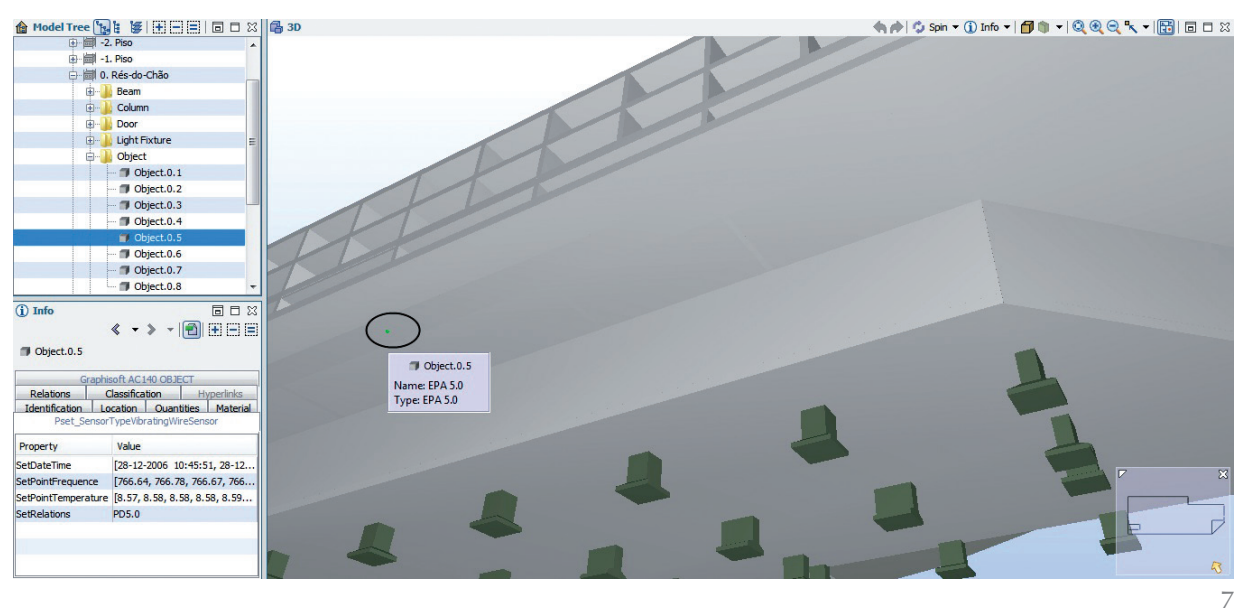

There has been an evolution in the number and variety of sensors included in the IfcSensortype class since the early versions of the model. From the initial inclusion of this class in model version $2 \times 2$ up to model version $2 \times 4$ ALPHA, there were 15 different sensor types. From model version $2 \times 4$ RC1 until the current RC2 version, 8 more sensor types have been included and one has been removed.

The existing specific property sets for each sensor have themselves evolved, as can be seen on Table 5, with addition and deletion of data fields and data properties. For example the temperature sensor type had the range, accuracy and time constant deleted from versions $2 \times 3 \mathrm{TC} 1$ to $2 \times 4 \mathrm{RC} 1$. Another example is the moisture sensor, which became a proper property set at version $2 \times 4 \mathrm{RC} 1$.

The authors believe that, as done in the past, it should be possible and advisable to expand the IFC model structure to include new sensor types, namely structural kinematic sensors such as LVDTs, inclinometers and strain gauges. These sensors are relevant because the data they collect can produce events and related tasks, as for example a structural failure can be detected and a consequent alarm can be raised. But, because these sensors are often used in the context of structural health monitoring, where the data is processed and analysed by structural specialists, they should have their own specific sensor type.

The sensors that presently exist are mostly environmental: thermometer, wind sensor, humidity sensor, etc. The sensors being proposed in this paper are structural or kinematic in nature. There could be a case for creating sensor groups according to this distinction, so as to help the user to better find a suitable sensor type as well as to better organise its information.

Table 5. Sensors evolution in IFC

\begin{tabular}{|c|c|c|c|c|c|c|c|}
\hline \multirow[t]{2}{*}{ Value / Name } & \multirow{2}{*}{$\begin{array}{c}\text { Property } \\
\text { Set }\end{array}$} & \multicolumn{6}{|c|}{$\begin{array}{c}\text { IFC Version } \\
\text { Added }(+) \text {, Removed }(-) \text {, Changed }(\Delta)\end{array}$} \\
\hline & & $<2 \times 2$ & $2 \times 2$ & $2 \times 3$ TC1 & $2 \times 4$ alpha & $2 \times 4 \mathrm{RC} 1$ & $2 \times 4$ RC2 \\
\hline CO2SENSOR & Yes & & $(+)$ & & & $(-)$ & \\
\hline CONDUCTANCESENSOR & Yes & & & & & $(+)$ & \\
\hline CONTACTSENSOR & Yes & & & & & $(+)$ & \\
\hline FIRESENSOR & Yes & & $(+)$ & & & & \\
\hline FLOWSENSOR & Yes & & & & & $(+)$ & \\
\hline GASSENSOR & Yes & & $(+)$ & & & $(\Delta)$ & \\
\hline HEATSENSOR & Yes & & $(+)$ & & & $(\Delta)$ & \\
\hline HUMIDITYSENSOR & Yes & & $(+)$ & & & $(\Delta)$ & \\
\hline IONCONCENTRATIONSENSOR & Yes & & & & & $(+)$ & \\
\hline LEVELSENSOR & Yes & & & & & $(+)$ & \\
\hline LIGHTSENSOR & Yes & & $(+)$ & & & $(\Delta)$ & \\
\hline MOISTURESENSOR & Yes $^{*}$ & & $(+)$ & & & $(\Delta)$ & \\
\hline MOVEMENTSENSOR & Yes & & & & & $(+)$ & \\
\hline PHSENSOR & Yes & & & & & $(+)$ & \\
\hline PRESSURESENSOR & Yes & & $(+)$ & & & $(\Delta)$ & \\
\hline RADIATIONSENSOR & Yes & & & & & $(+)$ & \\
\hline RADIOACTIVITYSENSOR & Yes & & & & & $(+)$ & \\
\hline SMOKESENSOR & Yes & & $(+)$ & & & $(\Delta)$ & \\
\hline SOUNDSENSOR & Yes & & $(+)$ & & & $(\Delta)$ & \\
\hline TEMPERATURESENSOR & Yes & & $(+)$ & & & $(\Delta)$ & \\
\hline WINDSENSOR & Yes & & & & & $(+)$ & \\
\hline USERDEFINED & No & & $(+)$ & & & & \\
\hline NOTDEFINED & $\mathrm{No}$ & & $(+)$ & & & & \\
\hline
\end{tabular}

Moisturesensor was used as a database object since IFC2x2, and only became a proper property set in IFC $2 \times 4 \mathrm{RC} 1$. 
As in other construction domains, storage and ownership of large volumes of SHM data can become a critical issue when designing and adopting an information system. On one hand, the management of continuous data collection systems can become unpractical due to the size of the files that are generated in the process. On the other hand, the entity responsible for collecting and registering the data, may not wish to share it. Both these problems can be effectively solved by maintaining SHM data separately from the main model itself, under the custody of the respective owner. Since SHM data is a subset of the main integrated data model, it is in effect an aspect model (28). Although this aspect model can be stored in a database, it would be preferable to use a standard IFC file that can be accessed by BIM tools. These aspect models can be merged using currently available open source BIM tools (29).

Currently, since the $2 \times 4 \mathrm{RC} 1$ version, the IFC model defines a sensor occurrence not as an IfcSensorType as in previous versions, but as a new model class, IfcSensor. This new model class can then be related to its generic sensor type information, if it exists, which is stored in the relevant IfcSensorType classes. The IfcSensorType defines the common type name, usage, properties, materials, ports, composition, assignments and representations. The IfcSensorType is related by use of an IfcRelDefinesByType relationship and can be accessed by the IsTypedBy inverse attribute (30).

For the tried example of the vibrating wire strain gauge, a generic custom property set was used, altered to suit the specific sensor data needs, as shown in Table 3 and Table 4 of Section 4 . In the spirit of the perceived dynamics of expansion and evolution of the IFC data model, the following new specific sensor property sets are proposed in Table 6 .

\section{CONCLUSIONS}

A standardized general building product model such as the IFC brings benefits with its application, but these benefits do not come without challenges. The application of structural monitoring sensors in buildings, connected to corresponding digital building design models, has the possibility to produce a degree of interoperability between the various intervening agents, where the sensors and the data acquisition and transmission equipment can be modeled, and their relation with the other building objects can be formalised. However, the process of obtaining a dynamic monitoring of the structural behavior, where the obtained data can be quickly and accurately transferred from sensors to BIM and con-
Table 6. Proposed new Property Sets for structural sensors

\begin{tabular}{|l|l|}
\hline Value / Name / Property Set & Description \\
\hline VIBRATINGWIRE & $\begin{array}{l}\text { A device that detects vibrations for the } \\
\text { extensions calculation. }\end{array}$ \\
\hline LVDT & A device that measures linear displacements. \\
\hline INCLINOMETER & $\begin{array}{l}\text { A device that measures angles of slope (or tilt), } \\
\text { elevation or depression of an object with } \\
\text { respect to gravity. }\end{array}$ \\
\hline FOILSTRAINGAUGE & A device used to measure the strain of an object. \\
\hline
\end{tabular}

sequently to a specific structural analysis software, potentially allowing for effective decision making and in-time interventions, is not part of current BIM functionality.

To determine the feasibility of integrating sensor data, BIM and structural analysis, a case study with a prototype data transfer model was performed. It was possible to model a building and the sensors in it, enabling the development of an integrated building and sensor data model with contextual data. Modeling, visualization and structural analysis tools were used, which served to cross-check the changes that were being introduced over time. Text editors permitted direct data entry and model changes in IFC language. However, the tested applications were not able to handle the entire modeling procedure conveniently. Users and software developers need an evaluation of BIM application capabilities because each of their requirements are different, so as to permit a better integration and hence allowing for software evolution.

During the analysis, the nature of specific sensor property sets was verified in the IFC model, with the majority of them being environmental sensors. It was possible to verify the ongoing developments of the existing specific property sets within the different IFC versions, although structural or kinematic sensors still do not exist. For this reason, an environmental sensor had to be adapted to fit in the modeled building as a kinematic sensor. Following the apparent evolution path of the IFC versions, a new group of sensors is proposed, the kinematic sensors.

Finally, in terms of the handling and management of the sensor data, the existing sensor types do not have the ability to store information, namely SHM data. However, generic custom property sets can and were used to do this task, having the need to be properly defined with the various sensor properties and data types.

\section{ACKNOWLEDGEMENTS}

The authors would like to thank the Portuguese Fundação para a Ciência e Tecnologia, FCT, for global financial support and in particular the financial support given for the Ciência 2008 scholarship. 


\section{REFERENCES}

(1) Eastman, C.; Teicholz, P.; Sacks, R.; Liston, K. (2011) BIM Handbook, A guide to building information modelling for owners, managers, designers, engineers, and contractors. 2nd ed., p. 650, Wiley, Haboken, New Jersey.

(2) Watson, A. (2011). Digital buildings - Challenges and opportunities. Advanced Engineering Informatics, 25(4): 573-581, doi: 10.1016/j.aei.2011.07.003.

(3) Grzybek, H. (2010). Inclusion of Temporal Databases with Industry Foundation Classes a basis for adaptable intelligent buildings, ICISO 2010 Proceedings of the Twelfth International Conference on Informatics and Semiotics in Organisations, pp. 24-31.

(4) Smith, D. K.; Tardif, M. (2009). Building Information Modeling: A Strategic Implementation Guide for Architects, Engineers, Constructors, and Real Estate Asset Managers. p. 216, Wiley, New Jersey.

(5) ISO; TC184 ISO 10303-1:1994 (1994). Industrial automation systems and integration - Product data representation and exchange - Part 1: Overview and fundamental principles. ISO.

(6) Yoshida, Y.; Yabuki, N. (2009). Development of a dynamic sensor data model with contexts for data mining from monitoring of infrastructures, SSMS2009 The 5th International Symposium on Social Management Systems.

(7) SAFE Software Industry Foundation Class STEP Files (IFC) Reader (2012)

(8) Khemlani, L. (2004). The IFC Building Model: A Look Under the Hood. (Online). Available: http://www.aecbytes.com/feature/2004/IFCmodel.html.

(9) Farrar, C. R.; Worden, K. (2007). An introduction to structural health monitoring. Philosophical transactions, Series A, Mathematical, physical, and engineering sciences, 365 (1851): 303-315, doi: 10.1098/rsta.2006.1928.

(10) Mufti, A.; Bakht, B.; Tadros, G.; Horosko, A.T.; Sparks, G. (2007). Civionics A New Paradigm in Design, Evaluation, and Risk Analysis of Civil Structures. Journal of Intelligent Material Systems and Structures, 18(8): 757-763, doi: 10.1177/1045389X06074572.

(11) Brownjohn, J.M.W. (2007). Structural health monitoring of civil infrastructure. Philosophical transactions, Series A, Mathematical, physical, and engineering sciences, 365(1851): 589-622, doi: 10.1098/rsta.2006.1925.

(12) Ko, J.M.; Ni, Y.Q. (2005). Technology developments in structural health monitoring of large-scale bridges. Engineering Structures, 27(12): 1715-1725, doi: 10.1016/j.engstruct.2005.02.021.

(13) Akinci, B. (2004). Using sensor systems and standard project models to capture and model project history for building commissioning and facility management. Facility Area Network Workshop.

(14) Li, H.; Ou, J.; Zhao, X.; Zhou, W.; Li, H.; Zhou, Z. (2006). Structural Health Monitoring System for the Shandong Binzhou Yellow River Highway Bridge. Computer-Aided Civil and Infrastructure Engineering, 21(4): 306-317.

(15) Magalhães, F.; Cunha, Á.; Caetano, E. (2008). Dynamic monitoring of a long span arch bridge. Engineering Structures, 30(11): 3034-3044, doi: 10.1016/j.engstruct.2008.04.020.

(16) TC184; ISO ISO 19393-11 2004. (2004). Industrial automation systems and integration Product data representation and exchange - Part 11: Description methods: The EXPRESS language reference manual. ISO.

(17) BuildingSmart. (2011). buildingSMART International Limited - Industry Foundation Classes [Online Documentation]. Available in http://www.iai-tech.org/.

(18) Solihin, W. (2010). Modeling for IFC with AutoCAD Architecture, Autodesk Inc.

(19) Hensen, J.; Augenbroe, G. (2004). Performance simulation for better building design, Energy and Buildings, 36(8): 735-736, doi: 10.1016/j.enbuild.2004.06.004.

(20) Augenbroe, G. P.; Wilde, D.; Moon, H. J.; Malkawi, A. (2004). An interoperability workbench for design analysis integration, Energy and Buildings, 36(8): 737-748, doi: 10.1016/j.enbuild.2004.01.049.

(21) Mufti, A. (2001). Guidelines for structural health monitoring, Design manual 2. ISIS Canada Corporation, Winnipeg, Manitoba.

(22) Wong, K.-Y. (2007). Design of a structural health monitoring system for long-span bridges. Structure and Infrastructure Engineering, 3(2): 169-185. doi: 10.1080/ 15732470600591117.

(23) Sousa, H.; Félix, C.; Bento, J.; Figueiras, J. A. (2011). Design and implementation of a monitoring system applied to a long-span prestressed concrete bridge. Structural Concrete, 12(2): 82-93. doi: 10.1002/suco.201000014.

(24) McNeill, D. K. (2009). Data management and signal processing for structural health monitoring of civil infrastructure systems Chapter 9 in Structural Health Monitoring of Civil Infrastructure Systems, pp. 283-304. V. M. Karbhari, Ed. CRC Press.

(25) Spearpoint M. J.; Dimyadi, J. A. W. (2007). Sharing Fire Engineering Simulation Data Using the IFC Building Information Model. MODSIM07, International Congress on ModeIling and Simulation.

(26) Monteiro, A.; Poças Martins, J. (2012). SIGABIM - a framework for BIM application. 38th IAHS World Congress.

(27) BuildingSmart IFCSensorTypeEnum. (2011). [Online]. Available in http://buildingsmart-tech. org/ifc/IFC2x4/rc2/html/schema/ifcbuildingcontrolsdomain/lexical/ifcsensortypeenum.htm.

(28) Augenbroe G. (1994). An Overview of the COMBINE project.

(29) BiMserver BiMserver. (2010). [Online]. Available: http://bimserver.org/. [Accessed: 05-Mar-2012].

(30) BuildingSmart IFCSensor. (2011). [Online]. Available in http://www.buildingsmart-tech. $\mathrm{org} / \mathrm{ifc} / \mathrm{IFC} 2 \times 4 / \mathrm{rc} 2 / \mathrm{html} / \mathrm{schema} /$ ifcbuildingcontrolsdomain/lexical/ifcsensor.htm. 